\title{
Predictive Model of Nonneoplastic Pathology after Endoscopic Resection of Gastric Epithelial Neoplasia
}

\author{
Tae-Geun Gweon, Byung-Wook Kim, Joon Sung Kim, Sung Min Park, Jeong Seon Ji, and Bo In Lee \\ Division of Gastroenterology, Department of Internal Medicine, Incheon St. Mary's Hospital, College of Medicine, The Catholic University of \\ Korea, Seoul, Korea
}

Background/Aims: The rate of nonneoplastic pathology (NNP) after endoscopic resection (ER) of gastric epithelial neoplasia (GEN) has been reported to be 3\%-7\%. However, to date, the associations of pretreatment characteristics with NNP have not been identified. The aim of this study was to develop a predictive model for NNP after ER. Methods: Among 817 patients who underwent ER for GEN, factors associated with NNP were identified by univariate and multivariate analyses. Weighted points considering the $\beta$ coefficient were allocated to each variable that was significant in the multivariate analysis. The predictive score was calculated by the total points. The area under the receiver operating characteristic curve (AUROC) was calculated for the predictive score. Results: The rate of NNP was $8.8 \%$. After multivariate analysis, poor demarcation from the background, no ulceration, a flat appearance, and low-grade dysplasia were significant factors predictive of NNP. One point each was allocated for no ulcer, flat appearance, and low-grade dysplasia. Two points were allocated for poor demarcation from the background. The predictive score ranged from 0 to 5 points. Patients were categorized as being at low risk $(0,1$, or 2 points) or high risk (3, 4 , or 5 points) for NNP. The AUROC was 0.82 (95\% confidence interval, 0.77 to 0.88 ; $p<0.01$ ). With a cutoff value of 2.5 , the sensitivity and specificity of the score for predicting NNP were 0.72 and 0.84 , respectively. Conclusions: We developed a model to predict NNP after ER. Endoscopic re-biopsy or re-evaluation by pathologists is strongly recommended for the high-risk group. (Gut Liver 2020;14:199-206)

Key Words: Gastric epithelial neoplasia; Endoscopic resection; Nonneoplastic pathology

\section{INTRODUCTION}

Endoscopic resection (ER) including endoscopic mucosal resection (EMR) and endoscopic submucosal dissection (ESD) is now considered as a standard method for the treatment of gastric epithelial neoplasia (GEN). ${ }^{1,2}$ Endoscopists often encounter nonneoplastic pathology (NNP) results after ER. The incidence of NNP results has been reported as 3\% to 7\%., ${ }^{3,4}$ Complete removal of tumor by forceps biopsy, mistargeting during ER, or overdiagnosis by pathologists have been suggested as main reasons of NNP results. ${ }^{5}$

Forceps biopsy cannot represent histology of the entire tumor, which contributes to discordance between the histology result of forceps biopsy and resected specimen. Although atrophic gastritis and intestinal metaplasia are risk factors for GEN, inflammatory changes of background gastric mucosa contribute to mistargeting of tumor and overdiagnosis. In Korea, where prevalence of gastric cancer is high, the rate of discordance was reported up to $40 \%$. $^{6-8}$

Previous studies suggested that small tumor size and low sampling ratios were risk factors for NNP results after ER., ${ }^{9,10}$ However, there is no definite criteria for small tumor size. Low sampling ratio, defined as estimated length of tumor divided by number of biopsy fragment, is not easy to calculate. Therefore, low sampling ratio is not commonly used in routine clinical practice. These previous studies are not helpful to reduce the incidence of NNP results. Unnecessary procedure is related to patient's inconvenience and increases medical costs. To date, there was no predictive model for NNP results. The aim of this study was to develop a new predictive model for NNP results after ER.

\footnotetext{
Correspondence to: Byung-Wook Kim

Division of Gastroenterology, Department of Internal Medicine, Incheon St. Mary's Hospital, College of Medicine, The Catholic University of Korea, 56 Dongsu-ro, Bupyeong-gu, Incheon 21431, Korea

Tel: +82-32-280-5052, Fax: +82-32-280-5987, E-mail: gastro@catholic.ac.kr

Received on December 17, 2018. Revised on March 18, 2019. Accepted on March 18, 2019. Published online January 7, 2020. pISSN 1976-2283 eISSN 2005-1212 https://doi.org/10.5009/gnl18557

@ This is an Open Access article distributed under the terms of the Creative Commons Attribution Non-Commercial License (http://creativecommons.org/licenses/by-nc/4.0) which permits unrestricted non-commercial use, distribution, and reproduction in any medium, provided the original work is properly cited.
} 


\section{MATERIALS AND METHODS}

\section{Study population}

We retrospectively reviewed the medical records of our patients who underwent ER for GEN or suspicious GEN between 2013 and 2016 at Incheon St. Mary's Hospital, a tertiary referral center, Korea. Patients who underwent ER for hyperplastic polyp were not eligible for inclusion. GEN was defined as gastric adenocarcinoma limited in mucosal or submucosal layer and/or dysplasia limited in mucosal layer. Exclusion criteria were as follows: (1) history of prior gastrectomy; (2) ER for the treatment of GEN previously; (3) ablation therapy before ER; (4) familial adenomatous polyposis; (5) specimen loss after ER; and (6) incomplete medical records. NNP results were defined as no GEN in resected specimen histologically (revised Vienna classification category 1 and category 2). ${ }^{11}$ Clinicopathologic characteristics in terms of age, sex, forceps biopsy pathology, resection method, histologic findings on resected specimen, and tumor location were analyzed. Helicobacter pylori status was checked by histology or rapid urease test (Shinsung Pharm Co. Ltd., Seoul, Korea). When gastroscopy with forceps biopsy and pathologic evaluation was performed outside of our hospital, they were defined as referred specimen. This study protocol was approved by the Institute Review Board of Incheon St. Mary's Hospital, the Catholic University of Korea (IRB number: XC17RADI0071).

\section{Endoscopic assessment and resection}

ER was done by six board certified endoscopists. Before treatment, screening gastroscopy with or without endoscopic ultrasound to confirm tumor existence and to look for the additional gastric neoplasia was done under physician's discretion. Abdominal computed tomography was done in case of gastric cancer. The tumor location was classified into three groups: the upper, middle, and lower third. Color and gross appearance of the tumor were recorded. ${ }^{12}$ Endoscopic ulcer included ulcer (mucosal defect with a definite crater), erosion (superficial defect without a crater), and ulcer scar with converging folds. ${ }^{5,13,14}$ Demarcation or delineation from background gastric mucosa was assessed as good or poor. Good demarcation was defined when any of the followings were met: presence of a demarcation line and color change of tumor compared to background mucosa. ${ }^{15,16}$ Atrophic gastritis was described according to KimuraTakemoto classification. ${ }^{17}$ Intestinal metaplasia was determined as the presence of whitish or erythematous nodular lesions and/ or presence of blue light crest on narrow band imaging. ${ }^{18,19} \mathrm{Re}-$ section method was chosen considering tumor location, forceps biopsy pathology, and size. ER was done using endoscope GIFH260 or H290 (Olympus, Tokyo, Japan). Before ER, narrow band imaging and chromoendoscopy using indigo carmine were done for determine the tumor margin. Resection margin was set with securing 1-2 mm of safety margin. EMR was done using snares (Olympus) and ESD was performed using hook knife, dual knife or insulated tip knife (Olympus). The size and area of the resected specimen were recorded. Resected specimen area was calculated as follows: long diameter $\times$ short diameter $\times \pi / 4$. Curative resection was defined when all of the followings met: (1) en bloc resection; (2) no vertical and/or lateral margin involvement; (3) no lymphovascular invasion; and (4) within expanded criteria for early gastric cancer. ${ }^{20}$

\section{Histologic assessment}

Tumor size, depth of invasion, histologic grade, tumor differentiation, the presence of lymphovascular invasion, and resection margin involvement were assessed by three pathologists. In case of NNP, it was consulted to another pathologist. NNP was finally diagnosed at least two among three pathologists

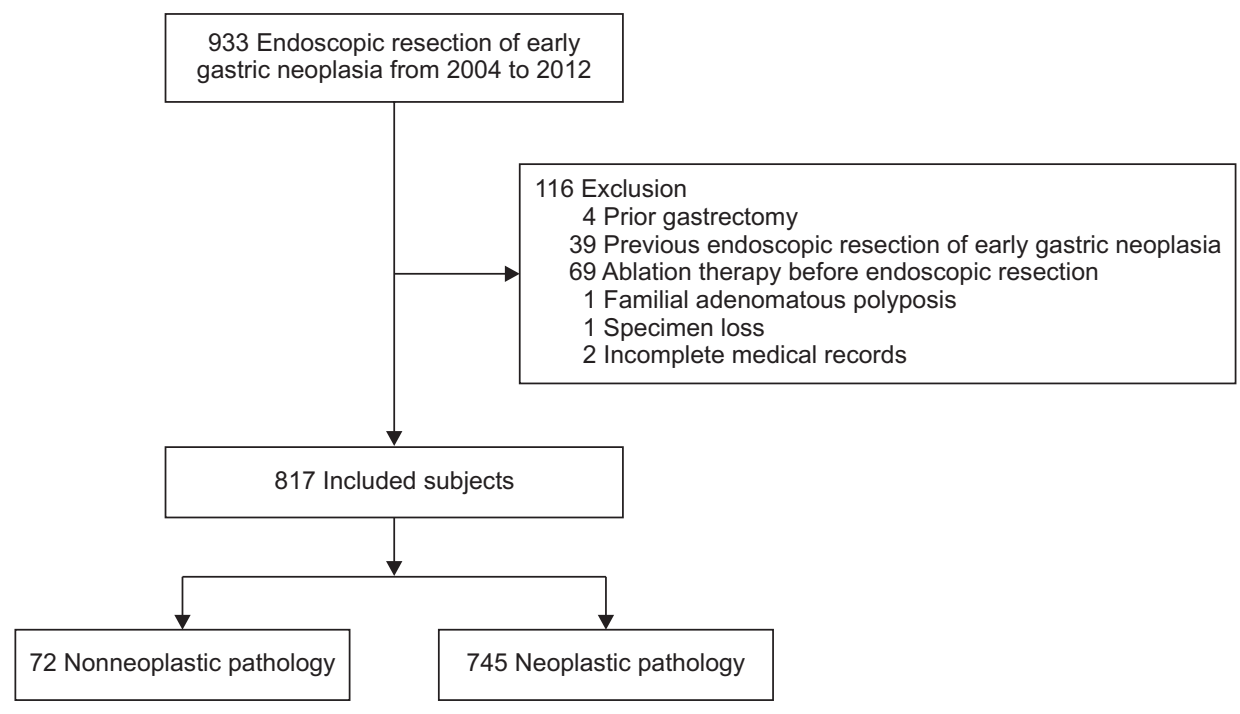

Fig. 1. Flow diagram for this study. 
agreed. To investigate the cause of NNP, histology of forceps biopsy specimen and resected specimen were re-evaluated. To investigate the interobserver variability of forceps biopsy results, forceps biopsy of GENs was reviewed by another pathologist. Forceps biopsy sample was selected from NNP and neoplastic pathology group at 1:1 ratio.

\section{Development of predictive model for NNP}

To establish a clinical risk score for predicting NNP, we assigned weighted points proportional to $\beta$ regression coefficient values for the factors determined in the multivariate analysis after initial ER. Total predictive score was the sum of each point. The rate of NNP at each predictive point was investigated. The area under the receiver operating characteristic curve (AUROC) was calculated for predictive score with 95\% confidence intervals (CI). Two authors (T.G.G. and B.W.K.) independently reviewed the key factors of endoscopic images which was significant in the multivariate analysis. Interobserver agreement was investigated.

\section{Statistical analysis}

Clinicopathologic characteristics were compared between the patients with or without NNP after ER. Univariate analysis was done to establish factors associated with NNP. For this analysis, we used the student t-test for continuous variables and the chisquare test or Fisher exact test for categorical variables. Multivariate analysis using logistic regression analysis was done with factors which were significant in the univariate analysis. Odds ratios and 95\% CI were calculated in the multivariate analysis. Cutoff point for NNP was selected using the Youden's index. ${ }^{21}$ All statistical analyses were performed using SAS software (SAS Institute, Cary, NC, USA). A p-value less than 0.05 was considered statistically significant.

\section{RESULTS}

\section{Univariate analysis}

Nine hundred and thirty-three patients underwent ER for 962 lesions during the study period. Of these, 116 patients were excluded for the following reasons: prior gastrectomy $(n=4)$; prior ER ( $n=39)$; ablation therapy before ER ( $n=69)$; familial adenomatous polyposis $(n=1)$; specimen loss $(n=1)$ and; incomplete medical records $(\mathrm{n}=2)$. After exclusion, 817 patients (850 lesions) were finally included in this study (Fig. 1). Initially, 27 of 817 patients (3.3\%) received 2 or more ER for multiple GEN. At initial ER, 72 lesions were identified as NNP in 72 patients. The rate of NNP was 8.8\% per patient (72/817) and 8.5\% per lesion (72/850), respectively. In patients with multiple GEN, single lesion was included: (1) more advanced lesion or (2) larger tumor size measured by histologic evaluation of resected specimen in case that the histologic grade was same. The clinicopathologic characteristics, which were obtained before ER, of the two groups are shown in Table 1. Age, male sex, percentage of patients who were referred from community hospital, tumor location, and status of $H$. pylori infection did not differ between the two groups. Type of atrophic gastritis, the proportion of intestinal metaplasia, result of forceps biopsy pathology, macroscopic type and color of tumor differed between the two groups. Only two patients whose forceps biopsy was cancer showed NNP (1.1\%). Poor demarcation was higher in the NNP group (44.4\% vs $5.5 \%, \mathrm{p}<0.01$ ). Ulcer was less frequent in the NNP group (8.3\% vs $36.6 \%, p<0.01)$. Estimated tumor size before resection was smaller in the NNP group (17.3 mm vs $21.3 \mathrm{~mm}, \mathrm{p}<0.01)$.

Table 1. Clinicopathological Characteristics of the Patients

\begin{tabular}{|c|c|c|c|}
\hline Characteristic & $\begin{array}{c}\text { Nonneoplastic } \\
\text { pathology } \\
(\mathrm{n}=72)\end{array}$ & $\begin{array}{c}\text { Neoplastic } \\
\text { pathology } \\
(\mathrm{n}=745)\end{array}$ & p-value \\
\hline Age, yr & $64.3 \pm 9.8$ & $65.1 \pm 9.5$ & 0.54 \\
\hline Male sex & $41(56.9)$ & $500(67.1)$ & 0.08 \\
\hline Referred patients & $54(75.0)$ & $523(70.2)$ & 0.39 \\
\hline Atrophy & & & $<0.01$ \\
\hline Closed & $38(52.8)$ & $246(33.0)$ & \\
\hline Open & $32(44.4)$ & $482(64.7)$ & \\
\hline None & $2(2.8)$ & $17(2.3)$ & \\
\hline Intestinal metaplasia & $52(72.2)$ & $626(84.0)$ & 0.01 \\
\hline Pathology before resection & & & $<0.01$ \\
\hline Cancer & $2(2.8)$ & $187(25.1)$ & \\
\hline High grade dysplasia & $5(6.9)$ & $116(15.6)$ & \\
\hline Low grade dysplasia & $62(86.1)$ & 394 (52.9) & \\
\hline Atypia & $3(4.2)$ & $48(6.4)$ & \\
\hline Tumor location & & & 0.09 \\
\hline Upper & $2(2.8)$ & $19(2.6)$ & \\
\hline Middle & $11(15.3)$ & $202(27.1)$ & \\
\hline Lower & 59 (81.9) & $524(70.3)$ & \\
\hline Macroscopic type & & & $<0.01$ \\
\hline Flat & $54(75.0)$ & $268(36.0)$ & \\
\hline Elevated & $14(19.4)$ & $343(46.0)$ & \\
\hline Depressed & $4(5.6)$ & $134(18.0)$ & \\
\hline Color of tumor & & & $<0.01$ \\
\hline Red & $29(40.3)$ & $457(61.3)$ & \\
\hline White or yellow & $43(59.7)$ & $288(38.7)$ & \\
\hline Demarcation & & & $<0.01$ \\
\hline Well & $40(55.6)$ & 704 (94.5) & \\
\hline Poor & $32(44.4)$ & $41(5.5)$ & \\
\hline Ulcer or ulcer scar & $6(8.3)$ & $273(36.6)$ & $<0.01$ \\
\hline Estimated tumor size, $\mathrm{mm}$ & $17.3 \pm 17.3$ & $21.3 \pm 10.7$ & $<0.01$ \\
\hline Helicobacter pylori* & 24/66 (36.4) & $307 / 702$ (43.7) & 0.25 \\
\hline
\end{tabular}

Data are presented as mean \pm SD or number (\%).

*Some data were missing. 


\section{Predictive model for NNP}

Table 2 shows the results of multivariate analysis. Poor demarcation, no ulcer, flat appearance, and low-grade dysplasia were significantly associated with NNP. Variables included one forceps biopsy result and three endoscopic characteristics. Endoscopic characteristics associated with NNP are shown in Fig. 2. Considering $\beta$ coefficient, one point was allocated in nonpresence of ulcer, flat appearance, and low-grade dysplasia. Two

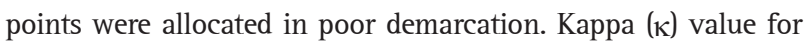
endoscopic findings was as follows: ulcer, 0.56; flat appearance, 0.69; poor demarcation, 0.71. Predictive score ranged from 0 to 5. Percentage of NNP in each point was as follow: point 0, 0.7\% (1/138); point 1, 3.2\% (6/186); point 2, 4.1\% (13/319); point 3, 20.3\% (22/108); point 4, 30.0\% (6/20); point 5, 52.2\% (24/46). AUROC of the predictive score was 0.82 ( $\mathrm{p}<0.01 ; 95 \% \mathrm{CI}, 0.77$ to 0.88 ) (Fig. 3). When adopting the cutoff point of 2.5, the sensitivity and specificity of the predictive score was 0.72 and 0.84 , respectively. Patients were categorized as low-risk group (points 0-2: 3.1\%, 20/643) or high-risk group (point 3-5: 33.8\%, 52/174) for NNP.

\section{Outcome of ER for GEN}

Comparison of ER between the patients who showed NNP or not was shown in Table 3. Patients who showed NNP received more EMR than patients with neoplastic pathology (40.3\% vs $22.6 \%, p<0.01)$. Long diameter and area of resected specimen in the neoplastic pathology group was bigger than in the NNP group $(30.4 \pm 10.9 \mathrm{~mm}$ vs $37.1 \pm 13.9 \mathrm{~mm}, \mathrm{p}<0.01 ; 632.4 \pm 410.8$ $\mathrm{mm}^{2}$ vs $939.4 \pm 632.4 \mathrm{~mm}^{2}, \mathrm{p}<0.01$, respectively).

When comparing the resection methods, NNP was higher in patients who underwent EMR than ESD (14.7\% vs $6.9 \%$, $\mathrm{p}<0.01$ ) (Table 4). Advanced histology including cancer and high-grade dysplasia was less common in EMR group than in ESD group (18.3\% vs 44.2\%, $\mathrm{p}<0.01$ ). Long diameter and area of resected specimen were smaller in EMR group than in ESD group $(27.4 \pm 11.3 \mathrm{~mm}$ vs $39.4 \pm 13.2 \mathrm{~mm}, \mathrm{p}<0.01 ; 528.6 \pm 444.0$ $\mathrm{mm}^{2}$ vs $1,034.6 \pm 786.3 \mathrm{~mm}^{2}, \mathrm{p}<0.01$, respectively). Predictive score for NNP was higher in EMR group than in ESD group (2.4 vs $1.6, \mathrm{p}=0.04)$.

\section{Results of interobserver variability for forceps biopsy}

A total of 144 lesions of forceps biopsy were reviewed by different pathologists. The $\kappa$-value for all forceps biopsy specimens was 0.51 . The $\kappa$-value for NNP and neoplastic pathology group

Table 2. Multivariate Analysis of Factors Associated with Nonneoplastic Pathology

\begin{tabular}{|c|c|c|c|c|c|}
\hline Characteristic & OR & $95 \% \mathrm{CI}$ & p-value & $\beta$ Regression coefficient & Point \\
\hline \multicolumn{6}{|l|}{ Atrophy } \\
\hline Open & 0.57 & $0.31-1.09$ & 0.07 & -0.54 & \\
\hline Others & 1 & Reference & & & \\
\hline \multicolumn{6}{|l|}{ Intestinal metaplasia } \\
\hline Presence & 0.47 & $0.31-1.15$ & 0.18 & -0.47 & \\
\hline None & 1 & Reference & & & \\
\hline \multicolumn{6}{|c|}{ Pathology before resection } \\
\hline Low grade dysplasia & 3.59 & $1.70-7.55$ & $<0.01$ & 1.25 & 1 \\
\hline Others & 1 & Reference & & & \\
\hline \multicolumn{6}{|l|}{ Macroscopic type } \\
\hline Flat & 3.32 & $1.75-6.20$ & $<0.01$ & 1.18 & 1 \\
\hline Others & 1 & Reference & & & \\
\hline \multicolumn{6}{|l|}{ Color of tumor } \\
\hline White or yellow & 1.37 & $0.69-2.43$ & 0.32 & 0.31 & \\
\hline Red & 1 & Reference & & & \\
\hline \multicolumn{6}{|l|}{ Demarcation } \\
\hline Poor & 5.21 & $2.79-10.75$ & $<0.01$ & 1.75 & 2 \\
\hline Good & 1 & Reference & & & \\
\hline \multicolumn{6}{|l|}{ Ulcer } \\
\hline None & 2.91 & $1.08-7.10$ & 0.02 & 1.08 & 1 \\
\hline Presence & 1 & Reference & & & \\
\hline Estimated tumor size & 0.98 & & 0.15 & -0.02 & \\
\hline
\end{tabular}

OR, odds ratio; $\mathrm{CI}$, confidence interval. 


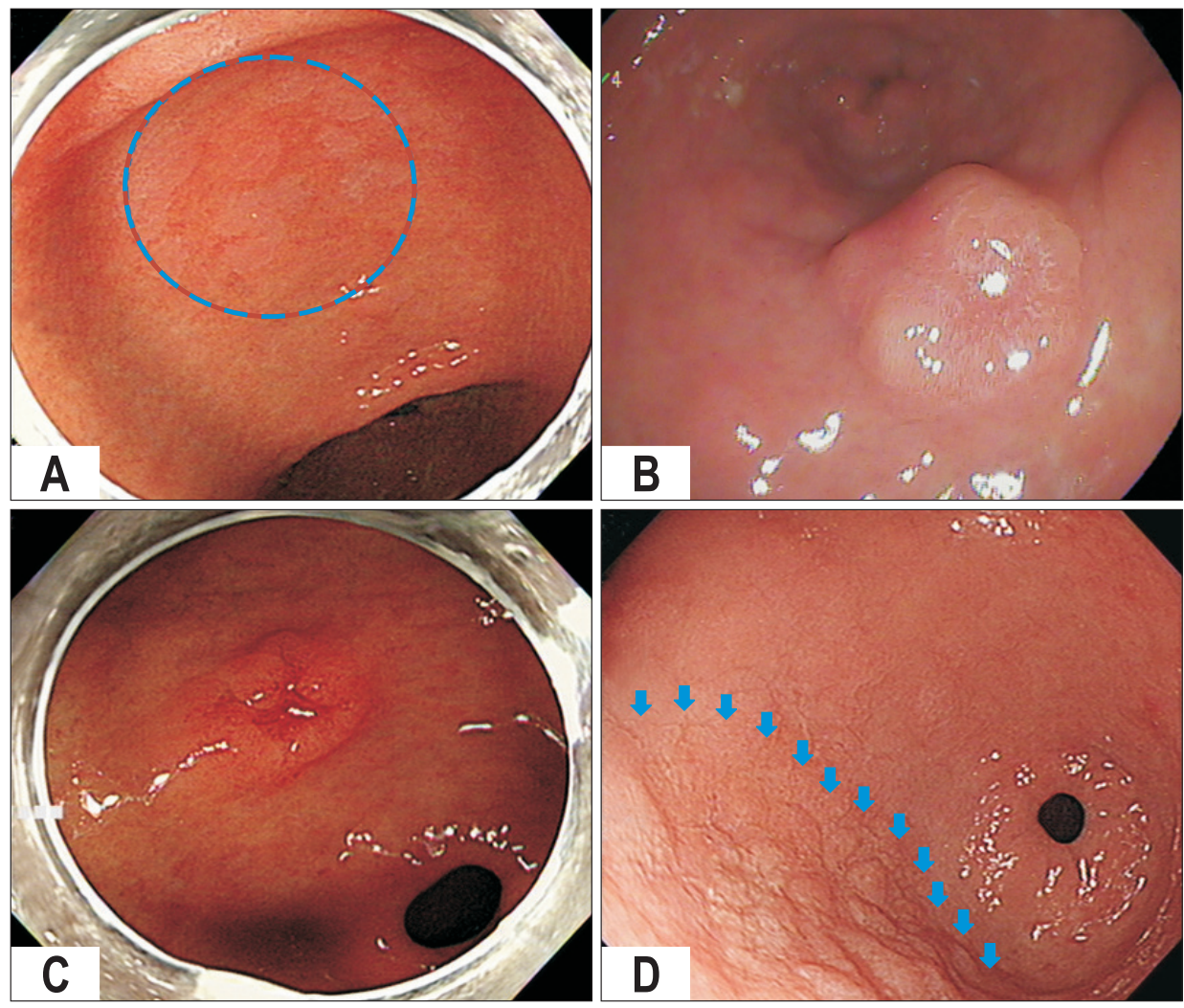

Fig. 2. Endoscopic characteristics associated with nonneoplastic pathology compared with endoscopic characteristics associated with neoplastic pathology. (A) A flat, nonulcerated lesion with poor demarcation from the background mucosa. Predictive score was 5 (flat appearance, lack of ulcer, low grade dysplasia at forceps biopsy, 1 point each; poor demarcation, 2 points). Neoplastic focus was not detected in the resected specimen (dotted line: neoplasm identified by endoscopist). (B) A 1.0-cm wide elevated tumor with good demarcation. Histologic result was low grade dysplasia after endoscopic submucosal dissection (ESD). Predictive score was 2 (lack of ulcer, low grade dysplasia at forceps biopsy, 1 point each). (C) A 1.0-cm wide IIa+IIc lesion with ulceration. Forceps biopsy histology and ESD specimen revealed high-grade dysplasia. Predictive score was 0. (D) A 3.0-cm wide flat nodular lesion with good demarcation from the background mucosa. Forceps biopsy histology and ESD specimen revealed low-grade dysplasia (arrows: border of neoplasm measured by endoscopist). Predictive score was 3 (flat appearance, lack of ulcer, low-grade dysplasia revealed by forceps biopsy, 1 point each).

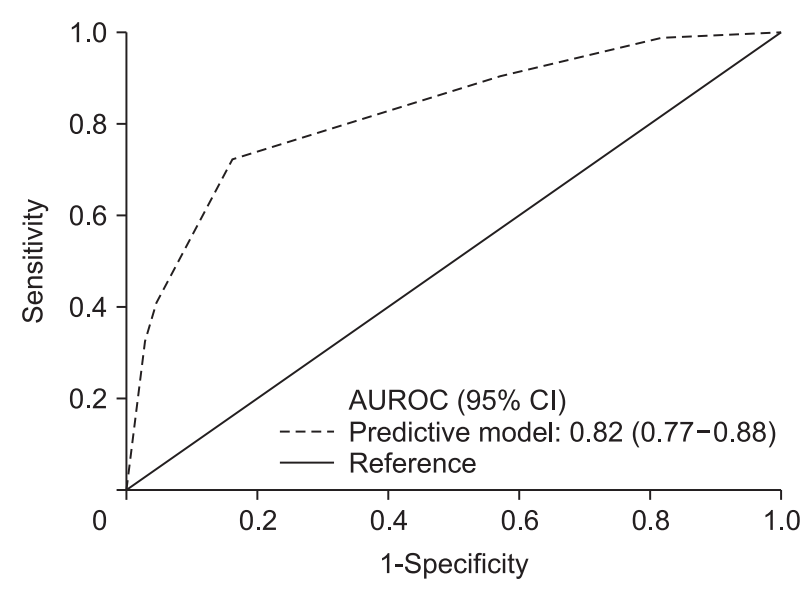

Fig. 3. Receiver operating characteristic curve for the predictive model.

AUROC, area under the receiver operating characteristic curve; CI, confidence interval.

was $0.29,0.56$, respectively. The $\kappa$-value between community pathologists and pathologists at our center was 0.41 . The $\kappa$-value among pathologists at our center was 0.62

\section{Analysis of NNP results}

Reasons of NNP results were as follows: complete removal $(n=30)$; overdiagnosis $(n=41)$; and mistargeting $(n=1)$. In the NNP, patients whose tumor was completely removed had smaller diameter of resected specimen $(25.1 \mathrm{~mm}$ vs $34.2 \mathrm{~mm}$, $\mathrm{p}<0.01$ ). Mistargeted GEN, which was found near ESD scar of initial resection, was treated after 3 months of initial ER.

\section{Follow-up after ER}

In the neoplastic pathology group, 708 patients were indicated for follow up after exclusion of 37 patients who underwent surgery or transferred to another hospital. Percentage of patients who underwent follow up gastroscopy more than once was 81.9\% (59/72) in the NNP group and 88.3\% (625/708) in the neoplastic pathology group, respectively. Secondary neoplasia, defined as gastric adenoma or cancer detected at the follow up gastroscopy, ${ }^{22}$ was found in 49 patients; NNP group, 6.8\% (4/59), versus neoplastic pathology group, 7.2\% (45/625), respectively. 
Table 3. Results of Endoscopic Resection in the Two Groups

\begin{tabular}{|c|c|c|c|}
\hline Characteristic & Nonneoplastic pathology $(n=72)$ & Neoplastic pathology $(n=745)$ & p-value \\
\hline Resection method & & & $<0.01$ \\
\hline EMR & $29(40.3)$ & $168(22.6)$ & \\
\hline ESD & $43(59.7)$ & 577 (77.4) & \\
\hline Resected specimen size, mm & $30.4 \pm 10.9$ & $37.1 \pm 13.9$ & $<0.01$ \\
\hline Resected specimen area, $\mathrm{mm}^{2}$ & $632.4 \pm 410.8$ & $939.4 \pm 632.4$ & $<0.01$ \\
\hline En bloc resection & $70(97.2)$ & $726(97.4)$ & 0.91 \\
\hline Curative resection & NA & $664(89.1)$ & \\
\hline Histology after resection & & & NA \\
\hline Nonneoplastic pathology & $72(100)$ & & \\
\hline Cancer & 0 & $393(52.8)$ & \\
\hline Low grade dysplasia & 0 & $217(29.1)$ & \\
\hline Tumor size by histology, mm & NA & $14.9 \pm 10.7$ & NA \\
\hline
\end{tabular}

Data are presented as number (\%) or mean \pm SD.

EMR, endoscopic mucosal resection; ESD, endoscopic submucosal dissection; NA, not available.

Table 4. Comparison of Resection Method

\begin{tabular}{lccr}
\hline \multicolumn{1}{c}{ Characteristic } & $\begin{array}{c}\text { EMR } \\
(\mathrm{n}=197)\end{array}$ & $\begin{array}{c}\text { ESD } \\
(\mathrm{n}=620)\end{array}$ & p-value \\
\hline Nonneoplastic pathology & $29(14.7)$ & $43(6.9)$ & $<0.01$ \\
Forceps biopsy pathology & & & $<0.01$ \\
$\quad$ Cancer & $15(7.6)$ & $174(28.1)$ & \\
High grade dysplasia & $21(10.7)$ & $100(16.1)$ & \\
Low grade dysplasia & $154(78.2)$ & $302(48.7)$ & \\
$\quad$ Atypia & $7(3.6)$ & $44(7.1)$ & \\
Estimated tumor size, $\mathrm{mm}$ & $13.9 \pm 6.6$ & $23.2 \pm 10.8$ & $<0.01$ \\
Resected specimen size, $\mathrm{mm}$ & $27.4 \pm 11.3$ & $39.4 \pm 13.2$ & $<0.01$ \\
Resected specimen area, $\mathrm{mm}{ }^{2}$ & $528.6 \pm 444.0$ & $1,034.6 \pm 786.3$ & $<0.01$ \\
Predictive score & $2.4 \pm 1.3$ & $1.6 \pm 1.2$ & 0.04 \\
\hline
\end{tabular}

Data are presented as number (\%) or mean \pm SD.

EMR, endoscopic mucosal resection; ESD, endoscopic submucosal dissection.

In the NNP group, secondary neoplasia was detected at a different location from initial ER. The reasons of NNP results were complete removal $(n=2)$ and overdiagnosis $(n=2)$. Three patients in the neoplastic pathology group received surgery for the treatment of secondary neoplasia. Remaining 46 patients in both groups underwent ER for the treatment of secondary neoplasia.

\section{DISCUSSION}

In the current study, we developed a predictive model for NNP results. The predictive model is easy to use and all the variables can be obtained before ER. Low grade dysplasia, flat appearance of tumor, no ulcer, and poor demarcation were significant factors after multivariate analysis. The AUROC of the predictive model was 0.82, which showed good accuracy in predicting NNP results.

The rate of NNP was $8.8 \%$ in this study, which was comparable with the results of previous studies. ${ }^{5,8,10-12}$ Several studies investigated reasons of NNP results. ${ }^{5,9,10}$ However, physicians cannot reduce the incidence of NNP with the results of previous studies. Therefore, it is more rational to develop a predictive model for NNP in clinical practice. There has been no report which identified predictive factors associated with NNP to date. The predictive model includes only four variables (3 endoscopic characteristics and forceps biopsy pathology) and score ranges 0-5 points. One point was assigned to low grade dysplasia, flat appearance, no ulcer and two points were assigned to poor demarcation. The $\kappa$-value for ulcer, flat appearance, and poor demarcation was $0.56,0.69$, and 0.71 , respectively. Strength of interobserver agreement was moderate to good. Rate of NNP increased up to 52\% with the increase of the score. AUROC was 0.82 , which indicates high accuracy of this novel predictive model. With the cutoff value of 2.5 , the sensitivity and specificity was 0.72 and 0.84 , respectively. Pathologic re-evaluation or endoscopic re-biopsy are indicated in patients with high risk for NNP (point 3-5). Three-fourths of patients who showed NNP were referred from community hospitals or primary clinics. Practically, it is not easy for physicians not to resect GEN which was diagnosed in their own hospital except contraindication or patients' poor medical condition. Hence, efforts to reduce NNP should be focused especially to patients who were referred from community hospital. This finding was supported by weaker interobserver agreement between community pathologists and pathologists at our center ( $\kappa$-value, 0.41) than those of our center ( $\kappa$-value, 0.62). Especially, interobserver agreement of forceps biopsy results was weaker in the NNP group. 
In contrast to high grade dysplasia, there are still controversies over the treatment of low grade dysplasia. ${ }^{1}$ Although low grade dysplasia is a precancerous lesion, its malignant potential is thought to be different from that of high grade dysplasia. ${ }^{11}$ Low grade dysplasia was proved to be low risk for progression to advanced lesion. ${ }^{23,24}$ However, a meta-analysis reported that $25 \%$ of low grade dysplasia was upgraded to high grade dysplasia or cancer after ER. ${ }^{25}$ Discrepancy between forceps biopsy and resected specimen include both upgrading and downgrading. Most previous studies focused on the predicting factors for low grade dysplasia which was upgraded after ER. Large tumor size $\geq 1-2 \mathrm{~cm}$, depressed morphology, uneven surface, and erythema were significant factors associated with upgraded histology. ${ }^{6-8}$ One previous study reported that absence of whitish discoloration was prognostic factor for advanced histology. ${ }^{26}$ Endoscopic characteristics which were investigated in the previous studies were comparable to those in our studies. In our study, non-presence of ulceration was an associated factor for NNP. Previous study showed that presence of ulceration was a prognostic factor for upgraded pathology result. ${ }^{8}$ Presence of ulcer is an important endoscopic characteristic for predicting downgrading or upgrading of histology. In the current study, flat lesion and poor demarcation were prognostic factors for NNP. Gastric neoplasia develop from the inflammatory gastric mucosa, which makes it difficult to distinguish gastric neoplasia and background gastric mucosa endoscopically or pathologically. ${ }^{27,28}$ Flat lesions with poor demarcation can be confused with intestinal metaplasia. In the current study, whitish tumor was a significant factor for NNP in univariate analysis. However, multivariate analysis showed that whitish color was not associated with NNP ( $p=0.32)$. Several studies suggested that small tumor size was risk factor for NNP results. ${ }^{9,10}$ In our study tumor size before resection was smaller in the NNP group in the univariate analysis. However, estimated tumor size was not significant for predicting NNP in the multivariate analysis. Because more than half of NNP resulted from overdiagnosis, the resected lesion may not be "true neoplasm." Therefore, it might be illogical to include tumor size for predicting NNP results. Low grade dysplasia at forceps biopsy was histologic variable associated with NNP. More than half of patients (55.8\%) received ER for low grade dysplasia at forceps biopsy. Rate of NNP who underwent ER for the treatment of low grade dysplasia was 13\%. On the other hand, the rate of NNP after resection of cancer was 1.1\%. This finding is in line with previous studies, in which low grade dysplasia was associated with NNP.,10

We included all patients who received EMR or ESD. Rate of NNP was higher in patients who received EMR than those who received ESD (14.7\% vs 6.9\%, p<0.01). We compared the clinicopathologic characteristics who underwent EMR and ESD to investigate whether resection methods have affected the results of NNP. Estimated tumor size was smaller in the EMR group. The predictive score for NNP was higher in the EMR group. There- fore, higher incidence of NNP in the patients who underwent EMR may have resulted in selection bias. Size of resected specimen was smaller in patients who showed NNP than neoplastic pathology. Furthermore, when we analyzed the reasons of NNP, size of resected specimen was smaller in patients whose tumor was completely removed by forceps than those with other causes. In our study, EMR was done when tumor was small and/or lowgrade dysplasia, which were the two main reasons for NNP.

EMR is recommend for the treatment of GEN $\leq 15-20 \mathrm{~mm}$ with less advanced histology. ${ }^{29-31}$ Furthermore, EMR is cost effective and less time consuming than ESD. The choice of resection method was proper in this study. In a previous study, the rate of NNP in the EMR and ESD was 3.6\% and 3.2\%, respectively $(\mathrm{p}=0.81)^{5}$ In that study endoscopists preferred ESD, because most of ER was done by ESD (95.5\%).

There are limitations to be addressed in this study. First, it was a retrospective study and some data were missing. However, our data were collected prospectively among cohort of our patients who underwent ER. We believe that our cohort is reliable because over 80\% of patients underwent follow up EGD. Second, sample size was relatively small. However, we included all patients during 4 years which were latest. Third, it was a single-center study. Interobserver agreement for endoscopic finding was evaluated by two endoscopists. External validation in prospective manner in another region or hospital is anticipated.

In conclusion, we developed a simple scoring system to predict NNP after ER. This predictive model may reduce the incidence of NNP. Endoscopic re-biopsy or pathology re-evaluation in case of high risk for NNP (points 3-5) is recommended.

\section{CONFLICTS OF INTEREST}

No potential conflict of interest relevant to this article was reported.

\section{AUTHOR CONTRIBUTIONS}

Study concept and design: T.G.G., B.W.K. Data acquisition, analysis, drafting of the manuscript, statistical analysis: T.G.G. Data interpretation: T.G.G., B.W.K. Critical revision of the manuscript for important intellectual content: J.S.K., S.M.P. J.S.J., B.I.L. Administrative, technical, or material support: T.G.G., B.W.K., J.S.K., S.M.P., J.S.J., B.I.L. Study supervision: B.W.K

\section{ORCID}

Tae-Geun Gweon

Byung-Wook Kim

Joon Sung Kim

Sung Min Park

Jeong Seon Ji

Bo In Lee https://orcid.org/0000-0002-0884-7228 https://orcid.org/0000-0002-2290-4954 https://orcid.org/0000-0001-9158-1012 https://orcid.org/0000-0003-0593-3320 https://orcid.org/0000-0003-2806-6039 https://orcid.org/0000-0002-0218-4136 


\section{REFERENCES}

1. Sung JK. Diagnosis and management of gastric dysplasia. Korean J Intern Med 2016;31:201-209.

2. Ryu SJ, Kim BW, Kim BG, et al. Endoscopic submucosal dissection versus surgical resection for early gastric cancer: a retrospective multicenter study on immediate and long-term outcome over 5 years. Surg Endosc 2016;30:5283-5289.

3. Choi MK, Kim GH, Park DY, et al. Long-term outcomes of endoscopic submucosal dissection for early gastric cancer: a singlecenter experience. Surg Endosc 2013;27:4250-4258.

4. Lee CK, Chung IK, Lee $\mathrm{SH}$, et al. Is endoscopic forceps biopsy enough for a definitive diagnosis of gastric epithelial neoplasia? J Gastroenterol Hepatol 2010;25:1507-1513.

5. Choi JM, Kim SG, Yang HJ, et al. Clinical outcomes of no residual disease in the specimen after endoscopic resection for gastric neoplasms. Surg Endosc 2016;30:610-618.

6. Cho SJ, Choi IJ, Kim CG, et al. Risk of high-grade dysplasia or carcinoma in gastric biopsy-proven low-grade dysplasia: an analysis using the Vienna classification. Endoscopy 2011;43:465-471.

7. Min BH, Kim KM, Kim ER, et al. Endoscopic and histopathological characteristics suggesting the presence of gastric mucosal high grade neoplasia foci in cases initially diagnosed as gastric mucosal low grade neoplasia by forceps biopsy in Korea. J Gastroenterol 2011;46:17-24.

8. Lim H, Jung HY, Park YS, et al. Discrepancy between endoscopic forceps biopsy and endoscopic resection in gastric epithelial neoplasia. Surg Endosc 2014;28:1256-1262.

9. Kim ES, Jeon SW, Park SY, et al. Where has the tumor gone? The characteristics of cases of negative pathologic diagnosis after endoscopic mucosal resection. Endoscopy 2009;41:739-745.

10. Yang MJ, Shin SJ, Lee KS, et al. Non-neoplastic pathology results after endoscopic submucosal dissection for gastric epithelial dysplasia or early gastric cancer. Endoscopy 2015;47:598-604.

11. Dixon MF. Gastrointestinal epithelial neoplasia: Vienna revisited. Gut 2002;51:130-131.

12. The Paris endoscopic classification of superficial neoplastic lesions: esophagus, stomach, and colon: November 30 to December 1, 2002. Gastrointest Endosc 2003;58(6 Suppl):S3-S43.

13. Hatta W, Gotoda T, Oyama T, et al. A scoring system to stratify curability after endoscopic submucosal dissection for early gastric cancer: “eCura system”. Am J Gastroenterol 2017;112:874-881.

14. Park SM, Kim BW, Kim JS, Kim YW, Kim GJ, Ryu SJ. Can endoscopic ulcerations in early gastric cancer be clearly defined before endoscopic resection? A survey among endoscopists. Clin Endosc 2017;50:473-478.

15. Yao K, Oishi T, Matsui T, Yao T, Iwashita A. Novel magnified endoscopic findings of microvascular architecture in intramucosal gastric cancer. Gastrointest Endosc 2002;56:279-284.
16. Yao K. The endoscopic diagnosis of early gastric cancer. Ann Gastroenterol 2013;26:11-22.

17. Kimura K, Takemoto T. An endoscopic recognition of the atrophic border and its significance in chronic gastritis. Endoscopy 1969;1:87-97.

18. Lin BR, Shun CT, Wang TH, Lin JT. Endoscopic diagnosis of intestinal metaplasia of stomach: accuracy judged by histology. Hepatogastroenterology 1999;46:162-166.

19. Pimentel-Nunes P, Dinis-Ribeiro M, Soares JB, et al. A multicenter validation of an endoscopic classification with narrow band imaging for gastric precancerous and cancerous lesions. Endoscopy 2012;44:236-246.

20. Peng LJ, Tian SN, Lu L, Chen H, Ouyang YY, Wu YJ. Outcome of endoscopic submucosal dissection for early gastric cancer of conventional and expanded indications: systematic review and metaanalysis. J Dig Dis 2015;16:67-74.

21. Youden WJ. Index for rating diagnostic tests. Cancer 1950;3:3235.

22. Gweon TG, Park JM, Lim CH, et al. Increased incidence of secondary gastric neoplasia in patients with early gastric cancer and coexisting gastric neoplasia at the initial endoscopic evaluation. Eur J Gastroenterol Hepatol 2014;26:1209-1216.

23. Rugge M, Cassaro M, Di Mario F, et al. The long term outcome of gastric non-invasive neoplasia. Gut 2003;52:1111-1116.

24. Yamada H, Ikegami M, Shimoda T, Takagi N, Maruyama M. Longterm follow-up study of gastric adenoma/dysplasia. Endoscopy 2004;36:390-396

25. Zhao G, Xue M, Hu Y, Lai S, Chen S, Wang L. How commonly is the diagnosis of gastric low grade dysplasia upgraded following endoscopic resection? A meta-analysis. PLoS One 2015 10:e0132699.

26. Kim YJ, Park JC, Kim JH, et al. Histologic diagnosis based on forceps biopsy is not adequate for determining endoscopic treatment of gastric adenomatous lesions. Endoscopy 2010;42:620-626.

27. Correa P. A human model of gastric carcinogenesis. Cancer Res 1988;48:3554-3560.

28. Correa P, Piazuelo MB. The gastric precancerous cascade. J Dig Dis 2012;13:2-9.

29. ASGE Standards of Practice Committee, Evans JA, Chandrasekhara $\mathrm{V}$, et al. The role of endoscopy in the management of premalignant and malignant conditions of the stomach. Gastrointest Endosc 2015;82:1-8.

30. Pimentel-Nunes P, Dinis-Ribeiro M, Ponchon T, et al. Endoscopic submucosal dissection: European Society of Gastrointestinal Endoscopy (ESGE) Guideline. Endoscopy 2015;47:829-854.

31. Park SM, Kim JS, Ji JS, Choi H, Lee BI, Kim BW. Efficacy of endoscopic mucosal resections for the management of small gastric adenomas with low-grade dysplasia. Scand J Gastroenterol 2015;50:1175-1182. 